\title{
Suitable Use of Injectable Agents to Overcome Hypoglycemia Risk, Barriers, and Clinical Inertia in Community-Dwelling Older Adults with Type 2 Diabetes Mellitus
}

\author{
Willy M. Valencia ${ }^{1,2,3} \cdot$ Hermes J. Florez ${ }^{1,3,4} \cdot$ Ana M. Palacio 1,3,4
}

Published online: 30 September 2019

(c) The Author(s) 2020, corrected publication 2020

\begin{abstract}
The management of type 2 diabetes mellitus in older adults requires a comprehensive understanding of the relationship between the disease (medical) and the functional, psychological/cognitive, and social geriatric domains, to individualize both glycemic targets and therapeutic approaches. Prevention of hypoglycemia is a major priority that should be addressed as soon as its presence or risk is detected, adjusting the target and therapeutics accordingly. Nonetheless, treatment intensification should not be neglected when applicable, consistent with recommendations from organizations such as the American Geriatrics Society and the American Diabetes Association, to reduce not only long-term macrovascular and microvascular complications (individualization), but also short-term complications from hyperglycemia (polyuria, volume depletion, urinary incontinence). Such complications can negatively impact the physical and cognitive function of older adults, worsen their quality of life, and additionally affect their families and society. We emphasize individualization, utilizing the multiple classes of antihyperglycemic agents available. Metformin remains as first-line therapy, and additional agents offer advantages and disadvantages that ought to be considered when developing a patient-centric plan of care. For selected cases, injectable therapies such as long-acting basal insulin analogs and glucagon-like peptide-1 receptor agonists can offer advantages to counter hypoglycemia risk, patient-related barriers, and clinical inertia. Furthermore, some injectable agents could potentially simplify regimens while providing safe and effective glycemic control. In this review, we discuss the use of injectable therapies for selected community-dwelling older adults, barriers to transition to injectable therapy, and measures aimed at removing these barriers and assisting physicians and their teams to transition older patients to injectable therapies when appropriate.
\end{abstract}

\section{Introduction}

Type 2 diabetes mellitus (T2D) is a chronic, progressive disease that can lead to multiple macrovascular and microvascular complications. It affects individuals, their families (time, non-paid caregiver costs, formal support), and society

Willy M. Valencia

willy.valencia-rodrigo@va.gov

1 Geriatrics Research, Education and Clinical Center (GRECC), Miami VA Healthcare System, 1201 NW 16th St., 11 GRC, CLC 207 A2, Miami, FL 33125, USA

2 Department of Humanities, Health and Society, Florida International University Herbert Wertheim College of Medicine, Miami, FL 33199, USA

3 Department of Public Health Sciences, University of Miami Miller School of Medicine, Miami, FL 33136, USA

4 Department of Medicine, University of Miami Miller School of Medicine, Miami, FL 33136, USA (healthcare costs and utilization, resources, and policies) [1]. The clinical course of T2D in older adults is heterogeneous and complex, impacted by age-related diseases (e.g., obesity, depression, and geriatric syndromes) and aging itself [2]. Successful and safe management of a patient with impaired physical or cognitive function will greatly rely on factors such as social support and resources [1-3]. Periodic monitoring and adjustment of targets and pharmacologic strategies require understanding the four geriatric domains in the older adult—psychological, medical, social, and functional—and optimizing targets and therapies in a timely fashion, while preventing complications (from hyperglycemia, hypoglycemia, or glycemic variability) [1-4]. Thus, major organizations highlight the need for treatment individualization, with special focus on the older population, incorporating geriatric assessments for function, cognition, and the burden of complications and comorbidities [5-10]. The common objective is to implement strategies that match the special needs of the aging population with diabetes [1-10]. 


\section{Key Points}

Older adults with type 2 diabetes mellitus are particularly vulnerable to developing low glucose levels, which may result in injury or death.

In selected patients, injectable therapies can offer advantages that include a simpler regimen and lower risk of low glucose events while reaching reasonable blood glucose targets.

Understanding the profile of injectable therapies, the concerns that patients and healthcare providers have about starting injectable therapies, and methods for implementation of these therapies, can enhance the plan of care in the right type of patient.

The therapeutic options to accomplish safe glycemic control are multiple, from oral monotherapy to more complex regimens, including multiple options for injectable agents [9]. Recent changes to updated guideline recommendations emphasize the consideration of cardiovascular benefits into the decision making for antihyperglycemic agents [9, 10]. The evidence supports the use of oral agents such as sodium-glucose co-transporter 2 (SGLT2) inhibitor among patients with T2D with co-existent coronary artery disease and heart failure [9, 10]. Alternatively, among patients in need of treatment modification, the use of injectable agents can be hindered by fear of side effects such as weight gain and hypoglycemia, as well as concerns related to treatment burden (costs and complexity) and negative medication beliefs [11, 12], and fear of needles [13]. Also, in our clinical experience, patients often oppose these agents due to feelings of disappointment and a sense of defeat by the disease itself. These barriers, as well as clinical inertia, lead to inadequate glycemic control [13].

Thus, the scope of this paper is to review the value of alternative therapeutic approaches such as those offered by injectable antihyperglycemic agents among communitydwelling older adults with T2D who, upon target individualization, remain uncontrolled, have high hypoglycemia risk on their established regimen, or for whom short-acting insulin is not applicable due to the complexity of the regimen. This review does not address the hospital, nursing home, or endof-life level-of-care settings. The literature search focused on peer-reviewed publications available in PubMed and EMBASE, using key words that connected the above-mentioned topics, using generic search terms (e.g., "injectable therapies in older adults with T2D") and more specific terms (e.g., the name of each injectable agent currently available, with search limits in older adults or aging population). The search limits included publications in the past 5 years, aiming to compile the newest reports on pharmacologic agents, guidelines, and opinions about their use in older adults. This review is intended for general practitioners and specialists caring for older adults with T2D, for whom treatment intensification is not contraindicated, but actually required, to facilitate discussions with patients and their caregivers, and to reduce hypoglycemia and treatment burden, especially considering that some newer injectable agents can offer the advantage of weekly regimens.

\section{Managing Type 2 Diabetes (T2D) in Older Adults}

The approach to treating an older adult with diabetes requires understanding that, on the one hand, factors specific to the disease and the aging patient affect diabetic physiopathology [14], and, on the other hand, the four geriatric domains are intertwined and affect diabetes self-management, self-efficacy, adherence, and the risk of medication errors and hypoglycemia (Fig. 1) [1-10]. Furthermore, the plan of care should incorporate functional status and quality of life, reducing, when possible, medicine burden, and actively identifying risks [15]. More recently, the need for a comprehensive geriatric assessment has been highlighted by an understanding of the role of frailty in diabetes and individualization of targets and strategies [16, 17]. Hypoglycemia risk is high, even in those with poor glycemic control [18], and it must be viewed as a serious adverse event [19]. Advancing age is the most common risk factor for hypoglycemia-related hospitalizations [20]. In parallel, diabetes is associated with impaired physical function (functional disability, frailty, and accelerated muscle loss), psychological function (depression, cognitive impairment, and dementia) [1-10], and social function (high diseaserelated burden, costs, and economic distress) [21, 22]. The management starts by individualizing targets and pharmacologic approaches based on disease duration, multimorbidity, hypoglycemia risk, feasibility and support, treatment costs, quality of life, and life expectancy [1-10].

\subsection{Adopting a Healthy Lifestyle and Environment}

Lifestyle modification is the foundation of T2D management. Strategies include (1) setting goals based on patients' input, language, numeracy, and cultural barriers; (2) integrating evidence-based guidelines and clinical information tools; and (3) encouraging connection with community resources, such as activity groups [3].

Intentional weight loss is not desirable in a 68-year-old patient with newly diagnosed cancer, a 75-year-old patient with dementia, or an 83-year-old patient with disability and dependence. However, older adults with T2D and obesity, who also have preserved physical and cognitive function, 


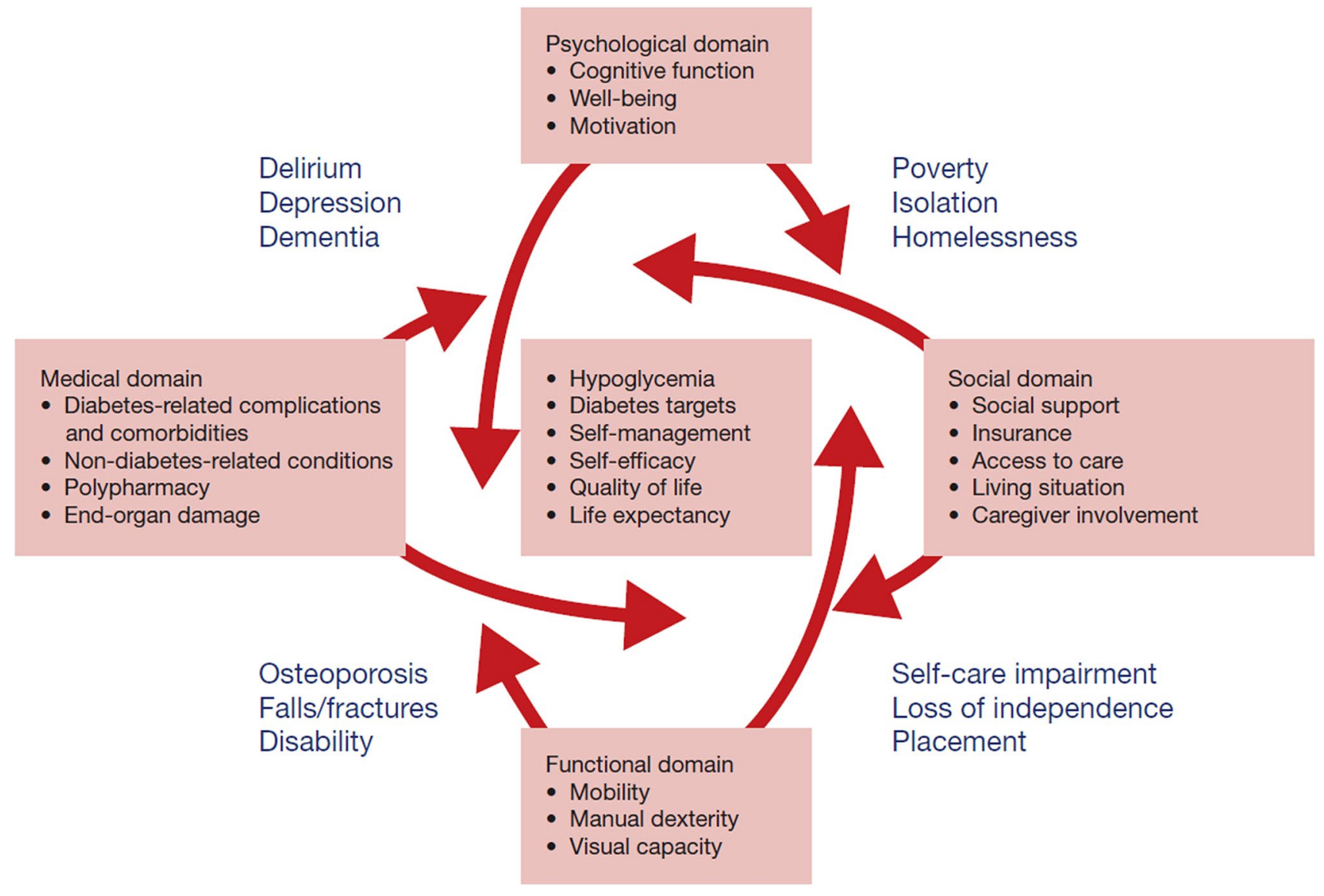

Fig. 1 A comprehensive approach to diabetes management in older adults. Evaluation and understanding of the four geriatric domains are fundamental for the implementation of best practices in older adults with diabetes. The four domains are intertwined, with interactions that impact diabetes self-management and self-efficacy, adherence, and risks. A healthy older adult can receive aggressive interventions in the setting of excellent self-management and self-efficacy skills and access to care and social support. As the person ages, not only does T2D run its natural course of progressive disease, but pharmaco-

can benefit from modest intentional weight loss as part of their plan of care [23]. Proper nutrition, physical activity, and the four types of recommended exercise can be feasible, effective, and successfully implemented [23]. Education is paramount, addressing the need to monitor and adjust medications to avoid hypoglycemia.

\subsection{Pharmacologic Treatment Beyond Metformin and Other Oral Antihyperglycemic Agents}

Metformin remains the first-line treatment for T2D [3, 9, 10]. However, diabetes is chronic and progressive, with altered pathophysiology, as mentioned above. As a consequence, older adults are likely to require additional therapies to achieve the desired individualized target. The newest guidelines of the American Diabetes Association [9] recommend logic management becomes more challenging because of multimorbidity, functional impairment, and cognitive decline, among others, which limit self-management and self-efficacy. Diabetes targets need to be reviewed and adjusted accordingly. Avoiding hypoglycemia is the priority, while preserving quality of life is a major outcome and marker of successful management. As life expectancy decreases, therapy will focus on the prevention of hyperglycemia emergencies, diabetic polyuria, and dehydration. T2D type 2 diabetes. Adapted from Valencia and Florez [1]

a step-wise approach, considering first the presence of established atherosclerotic cardiovascular disease (ASCVD), and implementation of SGLT2 inhibitors, or glucagon-like peptide 1 receptor agonists (GLP-1 RAs), because of their demonstrated cardiovascular disease benefit [9]. When ASCVD is not present, then the next big factor to consider is the presence or risk of hypoglycemia. Upon treatment individualization and implementation of the appropriate therapies, some older patients may achieve control, while others may need further treatment intensification to reach their individualized targets [1-10]. The subsequent selection of antihyperglycemic agents should be based on the pharmacologic profile and safety of the medication. Our review does not focus on T2D management in long-term care and skilled nursing facilities, for which separate guidelines are available [24]. Instead, we highlight the scenarios of community-dwelling older adults 
who, upon target individualization and therapy with metformin and the next-line agents, may still require treatment adjustments, individualized to their clinical presentation.

The most commonly used oral antihyperglycemic agents are summarized in Table 1 [1-3, 5-10, 25, 26].

\subsection{Injectable Non-insulin Agents}

GLP-1 RAs may be advantageous, as they have shown beneficial effects on body weight and are associated with a low risk of hypoglycemia in clinical trials [27].
Recently, significant attention has been placed on addressing potential additional cardiovascular benefits. While positive outcomes were observed in cardiovascular outcome studies with liraglutide (LEADER) [28], semaglutide (SUSTAIN) [29], and dulaglutide (REWIND) [30], the case was not the same with lixisenatide (ELIXA) [31] or exenatide (EXSCEL) [32]. A recent review focusing on cardiovascular outcomes of all GLP-1 RAs [33] summarized the available evidence on cardiovascular outcomes, and as not every agent has proven cardiovascular benefit, these benefits may not be a class effect. Moreover, there are observable differences in

Table 1 Oral pharmacologic options for older patients with type 2 diabetes

\begin{tabular}{|c|c|c|c|}
\hline Class & Agents & Advantages & Disadvantages \\
\hline Biguanide $[1-3,5-10]$ & Metformin & $\begin{array}{l}\text { Low cost } \\
\text { Improvement in dyslipidemia } \\
\text { Proven safety and effectiveness } \\
\text { No hypoglycemia } \\
\text { Lowers CV risk } \\
\text { Lower cancer risk than other therapies }\end{array}$ & $\begin{array}{l}\text { Lactic acidosis risk (rare) } \\
\text { Contraindicated when patient has renal } \\
\text { insufficiency or significant heart failure } \\
\text { GI side effects } \\
\text { Risk of vitamin B12 deficiency } \\
\text { May cause weight loss or GI side effects in } \\
\text { frail patients }\end{array}$ \\
\hline $\mathrm{SU}[1-3,5-10]$ & Glimepiride, glipizide & $\begin{array}{l}\text { Low cost } \\
\text { Extensive experience } \\
\text { Lowers microvascular risk }\end{array}$ & $\begin{array}{l}\text { Weight gain } \\
\text { Hypoglycemia } \\
\text { Caution recommended in patients with } \\
\text { renal, cardiac, or hepatic insufficiency } \\
\text { Possible increased risk of CVD and CV } \\
\text { mortality }\end{array}$ \\
\hline GLSi [1-3, 5-10] & Acarbose, miglitol & $\begin{array}{l}\text { Lower hypoglycemia and weight gain } \\
\text { than SU } \\
\text { Better CV safety than other oral agents } \\
\text { Reduces PPG excursions }\end{array}$ & $\begin{array}{l}\text { GI side effects (require gradual titration) } \\
\text { Potential hepatotoxicity with acarbose } \\
\text { Miglitol contraindicated in people with } \\
\text { renal failure } \\
\text { Moderate A1C lowering } \\
\text { Frequent dosing schedule }\end{array}$ \\
\hline TZD $[1-3,5-10]$ & Pioglitazone, rosiglitazone & $\begin{array}{l}\text { Low cost } \\
\text { Low hypoglycemia risk } \\
\text { Well tolerated and effective } \\
\text { Can be used in renal impairment }\end{array}$ & $\begin{array}{l}\text { Hepatic toxicity reported } \\
\text { Weight gain due to fluid retention } \\
\text { Increased risk of bone loss and fractures } \\
\text { Edema/heart failure } \\
\text { Possible increased CV risk }\end{array}$ \\
\hline DPP-4i [1-3, 5-10] & $\begin{array}{l}\text { Sitagliptin, vildagliptin, } \\
\text { saxagliptin, linagliptin, } \\
\text { alogliptin }\end{array}$ & $\begin{array}{l}\text { Low hypoglycemia risk } \\
\text { Well tolerated } \\
\text { Weight neutral } \\
\text { May help preserve } \beta \text { cells }\end{array}$ & $\begin{array}{l}\text { High cost } \\
\text { Requires renal dose adjustment (not } \\
\text { linagliptin) } \\
\text { Reports of worsening heart failure, head- } \\
\text { aches, elevated incidence of nasopharyn- } \\
\text { gitis, and respiratory tract infections } \\
\text { Data on long-term effects in older adults } \\
\text { are lacking }\end{array}$ \\
\hline SGLT2i $[1-3,5-10,25,26]$ & $\begin{array}{l}\text { Canagliflozin, dapagli- } \\
\text { flozin, empagliflozin } \\
\text { ertugliflozin }\end{array}$ & $\begin{array}{l}\text { Low hypoglycemia risk } \\
\text { Weight loss } \\
\text { Lower systolic blood pressure } \\
\text { Well tolerated } \\
\text { Efficacious and safe in older adults with } \\
\text { chronic kidney disease } \\
\text { Associated with lower CVD event rate } \\
\text { and mortality in patients with CVD }\end{array}$ & $\begin{array}{l}\text { High cost } \\
\text { GU infections } \\
\text { Volume depletion, hypotension, and diz- } \\
\text { ziness } \\
\text { Increased LDL-C } \\
\text { Concerns regarding long-term impact on } \\
\text { CV risk and carcinogenicity }\end{array}$ \\
\hline
\end{tabular}

Oral agents are beyond the scope of this review but are included here for easy reference

$A 1 C$ glycated hemoglobin, $C V$ cardiovascular, $C V D$ cardiovascular disease, $D P P-4 i$ dipeptidyl peptidase 4 inhibitors, GI gastrointestinal, GLS glucosidase inhibitors, $G U$ genitourinary, $L D L-C$ low-density lipoprotein cholesterol, $P P G$ postprandial glucose, $S G L T 2 i$ sodium-glucose cotransporter 2 inhibitor, $S U$ sulfonylureas, $T Z D$ thiazolidinediones 
the extent of the cardiovascular benefits between the GLP-1 RAs with positive outcomes.

On the other hand, while most studies did include older patients, few focused specifically on the older age group. The GetGoal-O study recruited patients aged $\geq 70$ years and randomized them to lixisenatide or placebo [34]. The results showed efficacy in reducing glycated hemoglobin (A1C), postprandial plasma glucose, and body weight. However, patients experienced more frequent nausea, vomiting, and diarrhea. Similarly, a prior study with liraglutide found that older age was associated with more gastrointestinal side effects [35]. Nevertheless, studies with liraglutide [36] and lixisenatide [37] have shown GLP-1 RAs can be well tolerated by older adults. Proper patient education and monitoring can enhance the initial implementation, and slow titration should be considered, particularly in this age group.

A 2019 cost-effectiveness analysis using the Swedish Institute of Health Economics (IHE) Diabetes Cohort Model compared different types of GLP-1 RAs with each other and with insulin [38]. The design was modeled on T2D patients who did not achieve control on metformin or basal insulin, and results favored the once-weekly formulation of semaglutide over lixisenatide and dulaglutide.

\subsection{Insulin}

Diabetes is a chronic progressive disease, and many older patients will eventually require, and benefit from, insulin therapy. We recommend educating patients about this fact earlier in their disease, where we observed less reluctance to initiate injectable therapies. The following is a review of studies addressing multiple insulin therapies.

In the Treat-to-Target trial, 756 patients, mean age 55 years, were randomly assigned to Gla-100 or neutral protamine Hagedorn (NPH) insulin. While both treatments were effective, those on Gla-100 experienced fewer documented hypoglycemia events [39]. More recently, a pooled analysis of five randomized clinical trials (RCTs) compared the safety of Gla-100 with NPH [40]. Regarding the subset of older adults (329 treated with Gla-100, 275 treated with NPH), greater event rates of hypoglycemia occurred in those receiving NPH, albeit without statistical significance. Notably, patients on NPH were receiving a once-daily dosage, which is not the proper practice based on the drug's half-life. A pooled analysis of 675 older patients with T2D found that patients treated with Gla-100 experienced better glycemic control and reduced incidence of hypoglycemia when compared with sulfonylureas, NPH, NPH 30/70, and insulin lispro (iLis) mix 75/25 [41].

With regard to fixed insulin combinations, the DURABLE trial was a 30-month, multicenter RCT that randomized 258 patients to insulin lispro (iLis) mix 75/25 (intermediateand short-acting iLis) and 222 patients to Gla-100 [42-45].
After 24 weeks, iLis resulted in slightly lower HbA1c levels and slightly higher percentages of patients achieving target HbAlc $<7.0 \%$ (53 mmol $/ \mathrm{mol}$ ), though these patients also experienced more weight gain and higher rates of overall hypoglycemia, but lower rates of nocturnal hypoglycemia [45]. While intermediate-acting preparations have been used as basal insulin, they require at least two injections per day and have greater hypoglycemia risk. We recommend avoiding them, except in the setting of economic limitations and lack of access to other injectable preparations (see Table 2) [1-3, 5-10, 46, 47].

Newer long-acting insulins, such as insulin glargine 300 units/mL (Gla-300) and insulin degludec (IDeg) 100 units $/ \mathrm{mL}$ and 200 units $/ \mathrm{mL}$, have been shown to provide a more constant pharmacokinetic profile with less hypoglycemia risk [48-50]. EDITION 3 was a multicenter, openlabel, parallel-group study that randomized 878 patients (age $57.7 \pm 10.1$ years, disease duration $9.8 \pm 6.4$ years) to Gla-300 or Gla-100 once daily for 6 months. The researchers found similar A1C reduction in both groups (change from baseline was $0.04 \%$ [95\% confidence interval (CI) -0.09 to 0.17 ] or $0.4 \mathrm{mmol} / \mathrm{mol}$ [ -1.0 to 1.9$]$ ) and lower hypoglycemia risk with Gla-300 (relative risk [RR] reduction of $24 \%$; RR $0.76,95 \%$ CI $0.59-0.99$ ) [48]. A post hoc, patient-level meta-analysis of data from EDITION 2 $(n=811)$ and EDITION $3(n=878)$ showed that patients treated with Gla-300 had comparable glycemic control when compared with those treated with Gla-100, with reduced confirmed or severe nocturnal hypoglycemia (RR 0.64, 95\% CI 0.48-0.85) and confirmed or severe hypoglycemia at any time of day (RR 0.77, 95\% CI 0.65-0.91) [51]. Similar results were observed in another post hoc metaanalysis, which included patients from EDITION 1, 2, and 3 and evaluated outcomes over a 12-month follow-up period [52]. Nocturnal hypoglycemia risk was lower with Gla-300 (RR 0.85, 95\% CI 0.77-0.92), and glycemic control defined as $\mathrm{A} 1 \mathrm{C}<7.0 \%$ without nocturnal hypoglycemia was achieved by $24 \%$ more patients with Gla-300 than with Gla-100 (RR 1.24, 95\% CI 1.03-1.50). Data from clinical trials is supported by real-world evidence utilizing electronic medical records. DELIVER Naïve compared insulin-naïve patients initiating Gla-300 and Gla-100. After 6 months' follow-up, patients treated with Gla-300 had significantly greater reductions in $\mathrm{A} 1 \mathrm{C}(-0.52 \mathrm{vs}-1.30 ; p=0.003)$, with more Gla-300-treated patients achieving A1C $<7.0 \%$ (21.9\% vs $17.4 \% ; p=0.003)$ without hypoglycemia [53]. In DELIVER 3, which studied older patients ( $\geq 65$ years) with T2D switching to Gla-300 from first-generation basal insulins (Gla-100 or insulin detemir), A1C reductions were greater/similar with Gla-300, and A1C goal achievement was similar in both cohorts, but Gla-300-treated patients generally had less hypoglycemia (event rate: adjusted rate ratio $0.63,95 \%$ CI $0.53-0.75 ; p<0.001$ ) [54]. Post-hoc and 
Table 2 Injectable pharmacologic options for older patients with type 2 diabetes

\begin{tabular}{|c|c|c|c|}
\hline Class & Agents & Advantages & Disadvantages \\
\hline GLP-1 RA [1-3, 5-10] & $\begin{array}{l}\text { Exenatide, liraglutide, dulaglutide, } \\
\text { lixisenatide }\end{array}$ & $\begin{array}{l}\text { Low hypoglycemia risk } \\
\text { Weight loss } \\
\text { Reduced PPG excursions } \\
\text { Reduces some CV risk factors } \\
\text { Once-daily and once-weekly } \\
\text { formulations }\end{array}$ & $\begin{array}{l}\text { High cost } \\
\text { GI side effects } \\
\text { Increased heart rate } \\
\text { Acute pancreatitis (exenatide and } \\
\text { liraglutide) } \\
\text { Acute renal failure (exenatide) }\end{array}$ \\
\hline $\begin{array}{l}\text { Intermediate-acting insulin }[1-3 \text {, } \\
5-10]\end{array}$ & $\mathrm{NPH}$ & $\begin{array}{l}\text { Long-term experience of use } \\
\text { Nearly universal response } \\
\text { Theoretically unlimited efficacy }\end{array}$ & $\begin{array}{l}\text { Significantly elevated risk of } \\
\text { hypoglycemia } \\
\text { Weight gain }\end{array}$ \\
\hline Long-acting insulin $[1-3,5-10]$ & $\begin{array}{l}\text { Insulin glargine } 100 \text { units } / \mathrm{mL} \text {, } \\
\text { insulin glargine } 300 \text { units } / \mathrm{mL} \text {, } \\
\text { insulin detemir, insulin degludec } \\
\text { (100 or } 200 \text { units } / \mathrm{mL})\end{array}$ & $\begin{array}{l}\text { Provides relatively uniform insulin } \\
\text { throughout the day } \\
\text { Nearly universal response } \\
\text { Theoretically unlimited efficacy } \\
\text { Lower hypoglycemia risk than } \\
\text { NPH }\end{array}$ & $\begin{array}{l}\text { Hypoglycemia } \\
\text { Weight gain } \\
\text { Patient reluctance }\end{array}$ \\
\hline Premix insulin $[9,10]$ & $\begin{array}{l}\text { 70/30 }(\mathrm{NPH}+\text { regular, } \\
\mathrm{NPH}+\text { aspart }), 75 / 25 \text { (lispro } \\
\text { protamine + lispro) }\end{array}$ & $\begin{array}{l}\text { Reduced number of injections } \\
\text { Long-term experience of use } \\
\text { Nearly universal response } \\
\text { Theoretically unlimited efficacy }\end{array}$ & $\begin{array}{l}\text { Hypoglycemia } \\
\text { Weight gain } \\
\text { Patient reluctance }\end{array}$ \\
\hline $\begin{array}{l}\text { Fixed-ratio combination GLP-1 } \\
\text { RA plus insulin }[46,47]\end{array}$ & $\begin{array}{l}\text { iGlarLixi (insulin glargine } \\
100 \text { units/mL + lixisenatide), } \\
\text { IDegLira (insulin degludec } \\
100 \text { units/mL + liraglutide) }\end{array}$ & $\begin{array}{l}\text { Reduced number of injections } \\
\text { Possible better glucose control and } \\
\text { increased safety compared with } \\
\text { individual components }\end{array}$ & $\begin{array}{l}\text { Moderate hypoglycemia risk } \\
\text { Maximal doses } \\
\text { Not feasible for patients who } \\
\text { require high insulin dosage }\end{array}$ \\
\hline
\end{tabular}

Short-acting synthetic insulin formulations are not mentioned as these are not usually started at the primary-care level because they require more specialized monitoring and titration, usually by an endocrinologist. Nonetheless, we emphasize that twice-daily regimens with combined insulins require an additional injection of short-acting insulin to cover lunch

$C V$ cardiovascular, $G I$ gastrointestinal, $G L P-1 R A$ glucagon-like peptide-1 receptor agonist, $N P H$ neutral protamine Hagedorn, $P P G$ postprandial glucose

real-world analyses offer important insight, especially when addressing the outcomes in the subpopulation of older adults [52]. The SENIOR study was the first prospectively designed study to address the efficacy and safety of insulin glargine in older people (age $\geq 65$ years) with T2D [55]. With a multinational, multicenter, randomized, open-label study design, 1014 patients were allocated to Gla-300 or Gla-100. While glycemic control was similar, the events of confirmed hypoglycemia were low and similar in both groups, with differences in the subgroup age $\geq 75$ years. In these patients, there were fewer events with Gla-300 than with Gla-100 (1.12 vs 2.71 , rate ratio $0.45,95 \%$ CI $0.25-0.83$ ). In parallel, the DEVOTE study randomly assigned 3818 patients to IDeg and 3819 patients to Gla-100, to assess cardiovascular safety [56]. The primary outcome (a composite of first occurrence of an adjudicated major cardiovascular event) occurred in 325 patients $(8.5 \%)$ with IDeg and in $356(9.3 \%)$ with Gla100 (HR $0.91,95 \%$ CI $0.78-1.06 ; p<0.001$ for non-inferiority), thus concluding IDeg was non-inferior to Gla-100 with respect to cardiovascular safety. Real-world data has shown that patients switching to IDeg from other basal insulins had significantly improved A1C $(0.58 \% ; p<0.001)$, without significant weight gain [57].
On the other hand, studies addressing long-acting basal insulins could offer potential applications, especially for the older population already facing polypharmacy or limitations to administration of injectable agents. A small pilot study in Japan found a thrice-weekly IDeg regimen was well tolerated in older adults with poorly controlled diabetes who had difficulty performing self-injection of insulin [58]. Using continuous glucose monitoring to assess and compare glycemic control, there were no differences between thrice-weekly versus once-daily injection groups for glucose $<70 \mathrm{mg} / \mathrm{dL}$ $(1.3 \pm 2.5 \%$ vs $2.4 \pm 3.1 \% ; p=0.39)$ or glucose $>200 \mathrm{mg} / \mathrm{dL}$ $(15.6 \pm 18.0 \%$ vs $7.2 \pm 12.1 \% ; p=0.22)$ [58]. Future studies confirming these results would support strategies where home-health nursing services (or family members, if well trained) could administer ultra-long-acting insulin formulations to elderly patients who cannot complete this task, thus becoming a good practical treatment option for these patients.

\subsection{Case Studies for Whom Injectable Agents May Be Considered for the Plan of Care}

Case Study 1: A 72-year-old female, with obesity, metabolic syndrome, diabetic microvascular complications, but 
without known ASCVD, whose parents are still alive (aged 98 and 97 years). Her antihyperglycemic regimen involves maximum-dose metformin and a sulfonylurea. Her most recent glycated hemoglobin was $11 \%$. She has a prior history of gallbladder disease and pancreatitis, and dipeptidyl peptidase 4 inhibitors and GLP-1 RAs are not an option for her. Adding a SGLT2 inhibitor as an oral agent can be an option, but due to the degree of elevation of A1C, she needs to be started on long-acting insulin, to be titrated by fasting glucose levels, while improving lifestyle to enhance postprandial control, with reassessment in 3 months to evaluate the need to add another agent.

Case Study 2: A 79-year-old male, with obesity, metabolic syndrome, microvascular and macrovascular complications, including ASCVD and heart failure, who lives independently at home, with only minor cognitive decline and no functional impairments, no falls, and no prior hypoglycemic events. His regimen includes metformin, an SGLT2 inhibitor, and basal insulin (0.9 units/ $\mathrm{kg}$ /day). However, his most recent A1C was $9 \%$, and fasting glucose levels averaged $110 \mathrm{mg} / \mathrm{dL}$. Therefore, adding more basal insulin is not going to offer postprandial control. The patient can benefit from multiple options, including both oral agents and injectable agents. Treatment individualization requires understanding the costs and accessibility, and the patient may consider a cheaper medication, such as a sulfonylurea, but needs to monitor weight and hypoglycemia risk. At the 3-month follow up, A1C had improved to $8 \%$ (which is on target). However, the patient reported four events of hypoglycemia per week (despite being told to report to the team, the patient misunderstood and thought the hypoglycemic events were to be expected. Luckily, there were no adverse events from the hypoglycemia, since they all occurred at home). The team evaluated the alternatives that would offer similar glycemic success, but with less risk of hypoglycemia.

\section{Barriers to Appropriate Transition to Injectable Antihyperglycemic Therapies}

Initiating and scaling injectable therapies in older adults present a variety of challenges. A recent systematic review identified three main themes as barriers [59]: (1) individual-fear of pain and injections, and concerns about the side effects, including hypoglycemia; (2) healthcare professional-poor knowledge and skills, clinical inertia, fear of hypoglycemia, and language barriers; (3) system-related barriers-not having enough time to manage dose adjustments and monitor potential side effects, and lack of educational resources.

\subsection{Hypoglycemia Risk and Fear of Hypoglycemia}

Older adults with diabetes are at increased risk of hypoglycemia [1-4, 9, 11, 20]. Hypoglycemia-related hospital admissions are nearly two-fold higher for patients aged $\geq 75$ years compared with those aged 65-74 years [60]. Consequences include dysrhythmias [61] (especially in those with cardiomyopathy) and accidents, falls, and related fractures [62]. Undoubtedly, preventing and minimizing hypoglycemia risk is one of the most important factors for determining glycemic goals and therapeutic approach [3, 9]. However, misunderstanding this approach by not increasing therapies to reach targets leads to clinical inertia.

\subsection{Patient-Related Barriers}

Personal barriers include perceived loss of personal control over treatment, the feeling of failure to control diabetes with oral agents, decreased flexibility, and increased inconvenience [9]. From a social perspective, negative reactions to insulin use from other people, the stigma and discrimination associated with the use of needles, and interference with social and work activities have been identified [59]. Finally, financial barriers can be due to increased diabetes healthcare costs, especially as older adults present multimorbidity and polypharmacy [1-3, 5-10].

\subsection{Clinical Inertia: Delayed Initiation of Appropriate Therapy}

Clinical inertia is a complex, multifactorial problem resulting from patient and physician barriers to treatment intensification [63]. A recent retrospective study from a US managed-care claims database of patients with uncontrolled T2D found that up to $72.8 \%$ of these patients experienced clinical inertia [64]. Of these, only up to $6.2 \%$ intensified treatment with insulin. Remarkably, a key barrier was older age itself.

Clinical inertia has important health care consequences. A 1-year delay in insulin initiation, in conjunction with poor glycemic control, significantly increases the risk of T2D complications, including myocardial infarction, heart failure, and stroke [65]. A retrospective cohort study of patients with T2D, grouped per clinical inertia (failure to initiate insulin within 3 months of an A1C level $\geq 9.0 \%$ ( $75 \mathrm{mmol} /$ mol) despite taking two oral antidiabetic drugs), found that clinical inertia was associated with a significantly shorter median time to progression of diabetic retinopathy $(p=0.02)$ and a higher incidence of diabetic retinopathy progression (10 vs 2.2 cases per 1000 person-months; $p=0.003$ ) [66]. Receiving treatment from a general practitioner was the strongest risk factor for clinical inertia. Another retrospective study reported that in patients aged $\geq 65$ years with T2D, 
mean time of exposure above A1C 7.0\% (53 mmol/mol) was 15 months [67].

A 2014 study evaluated the implementation of injectable agents between 2000 and 2009 in 51,771 patients with T2D who were receiving two oral agents and were followed for 2 years [68]. The majority (79.3\%) was started on a third oral agent compared with those started on insulin (13.3\%) or a GLP-1 RA (7.4\%). Those started on insulin had greater improvements in glycemic control.

A 2017 analysis of $>10,000$ individuals from a US clinical practice found that patients who were older (adjusted odds ratio [OR] $0.975,95 \%$ CI 0.971-0.979) and had higher A1C values (OR 0.741, 95\% CI 0.721-0.761) and Diabetes Complications Severity Index scores (OR 0.870, 95\% CI 0.848-0.892) were significantly less likely to be prescribed a GLP-1 RA compared with basal insulin [69]. While we did not find any European study of similar design, a 2017 report from a very large database ( $>400,000$ patients) from Italy, The Netherlands, Spain, and the UK, described injectables as being used mostly as third-line agents [70]. The main factors driving treatment choice at any stage of intensification were older age, A1C, body mass index, renal and cardiac morbidity, and treatment history.

\section{Transition to Injectable Agents to Overcome Hypoglycemia Risk, Patient-Related Barriers, and Clinical Inertia}

Once basal insulin is indicated as the next-best step for intervention, the provider must first address hypoglycemia risk and patient-related barriers. Notably, as we describe in the upcoming section, many newer injectable agents offer reduced hypoglycemia risk and can effectively help the patient to reach the individualized target and accomplish glycemic control. We present a summary in Table 3 [1-10, 59-67].

\subsection{Reducing Hypoglycemia Risk}

Hypoglycemia events require a clear understanding of their etiology to avoid a recurrence. Details in the history may reveal that the patient accidentally injected the correct dose twice because of forgetting an earlier dose, or that the patient was interrupted during a meal that remained unfinished. In both scenarios, the regimen may remain effective and safe if the events are isolated and conditions do not change. Recurrent events can be a sign of cognitive decline or early self-care deficits. Glycemic targets need to be adjusted, and further coordination of services (formal or informal) will be required in order to deliver the injectable therapeutic plan and to avoid hypoglycemia.
Despite concerns regarding hypoglycemia risk, several studies have demonstrated that many injectable therapies can be safe when properly implemented. Beyond the known low risk of hypoglycemia with the most commonly used long-acting basal insulins (Gla-100 and detemir), newer formulations include more concentrated and longer-acting basal insulins. The analyses from the EDITION studies demonstrated a significantly lower risk of hypoglycemia with Gla-300, with fewer participants reporting nocturnal or severe hypoglycemia episodes, in both insulin-naïve [48] and insulin-experienced [49] patients. These findings were corroborated in the SENIOR study [55]. Similarly, IDeg has demonstrated reduced rates of nocturnal severe hypoglycemia compared with Gla-100 in patients with T2D [56].

Regarding the time of administration, data from two phase III, 26-week RCTs that compared IDeg with daily Gla100 showed hypoglycemia episodes were greater when IDeg was administered at night rather than in the morning [71]. Basal insulin is usually administered at night to adjust dosage based on the next day's first fasting serum glucose, but switching to morning administration, ideally after a steady effective dose has been established, may decrease events. The principle of "start low and go slow" does not preclude, but rather facilitates the process to further titrate medications to accomplish the individualized target goals.

On the other hand, GLP-1 RAs offer options from twicedaily (exenatide) to once-weekly (semaglutide, exenatide) treatment. A recent systematic review indicates that longerduration GLP-1 RAs, such as once-weekly exenatide, may have less hypoglycemia risk than short-acting exenatide [72].

While the combination of injectable agents (e.g., basal insulin with pre-meal insulin, basal insulin with GLP-1 RAs) may fall under the specialist care of an endocrinologist, newer options are becoming available, with fixed dosages that could feasibly be implemented at the primary-care level. For example, short-acting GLP-1 RAs added to basal insulin resulted in a reduced number of hypoglycemia events when compared with the addition of short-acting insulin [73]. In this study, a subset of subjects were older. On the other hand, two fixed-ratio combinations of basal insulin plus GLP-1 RA have been approved and have demonstrated potential advantages. iGlarLixi (a combination of insulin glargine 100 units/ $\mathrm{mL}$ and lixisenatide once daily) demonstrated greater glycemic control compared with the individual components, with no increased risk of hypoglycemia [74]. IDegLira (a combination of IDeg and liraglutide once daily) achieved glycemic control superior to that of IDeg at equivalent insulin doses, without an increased risk of hypoglycemia and with the benefit of weight loss [75]. 


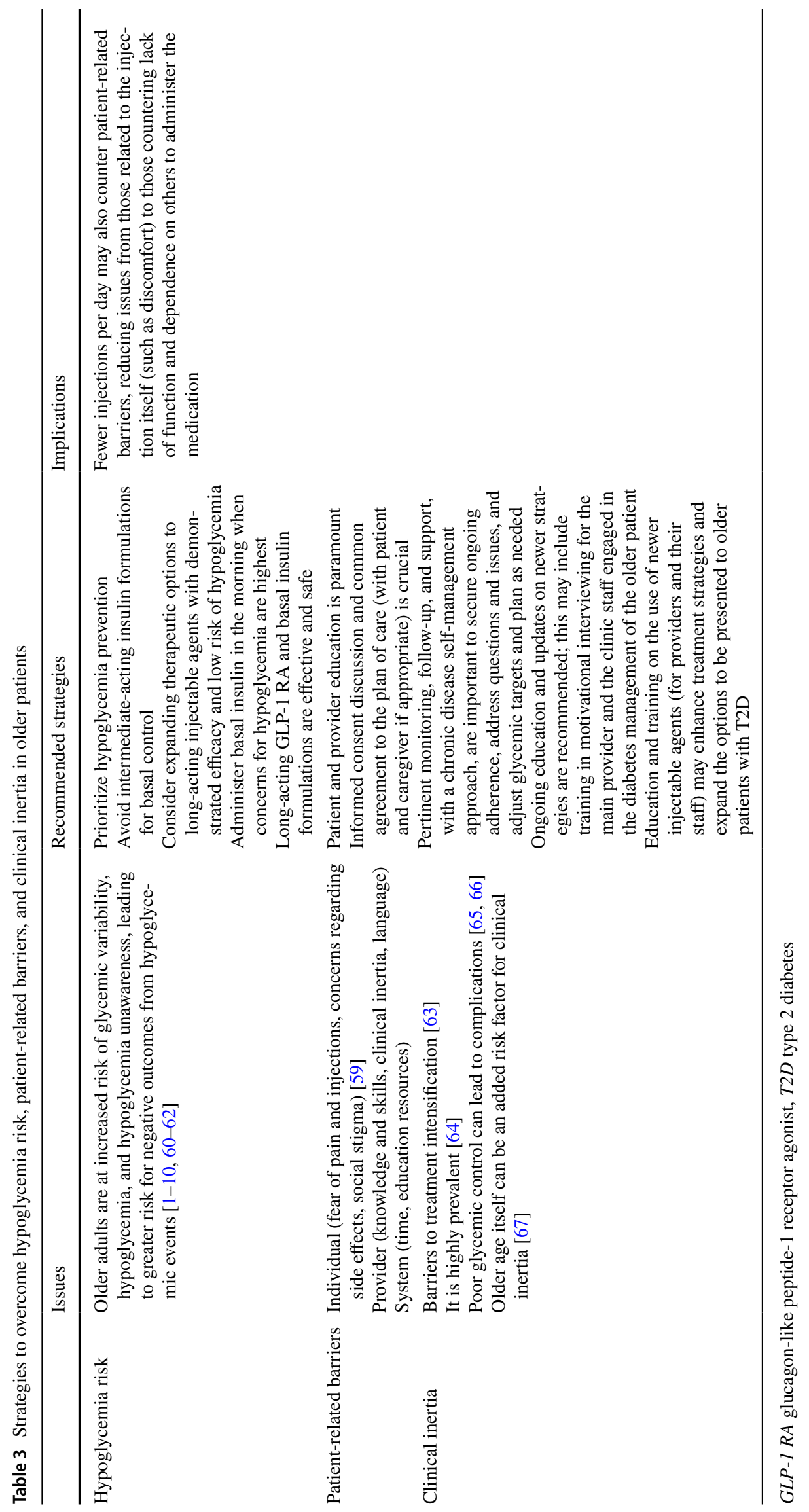




\subsection{Reducing Patient-Related Barriers}

Providers must identify the reasons for patients' ambivalence towards treatment, weighing views regarding advantages and disadvantages, and set clear goals and strategies to overcome the treatment barriers. Trained coaches can deliver an intervention at the point of care or via telephone.

All patients should be taught that as diabetes progresses, they may require basal insulin and, in the future, they might also need bolus-insulin dosing to better manage mealtime hyperglycemia exposure [9].

Improved patient and caregiver education are crucial for ensuring the successful transition to injectable therapies. Attention should be paid to dosage and self-management [60]. Interventions should include hands-on demonstrations of insulin injection, together with increased support from healthcare providers, using trained staff to remove time constraints, and regular follow-up via clinic visits or telephone calls.

In parallel, cognitive behavior strategies, such as motivational interviewing, may also help patients to improve self-efficacy and adherence to chronic medications [76]. Providers and staff may be trained to improve delivery of interventions to patients [60].

Previous reports indicate that pen-delivery devices are effective, improve convenience and flexibility, and may improve patients' confidence [77]. While the reduction of social stigma is still relevant for older adults, a greater advantage of pen delivery over the vial-and-syringe method is the greater ease of use for those with decreased physical dexterity. A database study in older adults with T2D using insulin pens compared with vial-and-syringe administration reported improved adherence and persistence with insulin therapy in the pen group [78].

Remarkably, despite the higher drug costs for pen devices, a claims database analysis did not find increased total allcause or diabetes-related healthcare costs when compared with vial and syringe and, additionally, reported lowering of hypoglycemia rates [79]. The latter could decrease costs related to emergency-room visits and hospitalizations.

Despite the lack of studies focused on older adults in specific settings, we have previously suggested that newer, once-weekly injectable GLP-1 RAs may be used instead of long-acting insulin in older patients with impaired mobility, limited social support, or a combination of these [1]. DURATION-3 was an RCT that compared once-weekly exenatide with daily Gla-100 in 456 patients with an average age of 58 years [80]. The researchers found a modest advantage $(0.16 \%$ greater reduction in $\mathrm{A} 1 \mathrm{C})$ in favor of the long-acting exenatide, yet we note their success in implementing a noninsulin injectable agent required only once-weekly administration in addition to oral agents to accomplish glycemic targets. The 3-year follow-up of these patients indicated sustained efficacy, which could enhance adherence and reduce barriers by reducing the number of injections and services required [81].

When treatment requires intensification, injectable therapies must be balanced with the treatment burden and the consequences of a delayed or missed insulin dose [11]. A 'basal-bolus' regimen (i.e., basal insulin and short-acting insulin before meals) adds up to at least four injections and four fingerstick fasting serum glucose measurements per day. This can be burdensome for both independent older adults as well as for those who rely on caregivers for their management. The availability of newer, improved (less thumb force and time needed to inject insulin) pen needles can mitigate the discomfort due to injections and is associated with improved patient satisfaction [82]. Thus, newer fixed-ratio combination agents, IDegLira or iGlarLixi, could reduce the number of injections while offering basal glycemic control and postprandial glucose control from the GLP-1 RA. In parallel, educational interventions and the use of telehealth technology can help overcome barriers to adherence and resistance to therapy. Strategies may include health coaching interventions, with or without the use of mobile-phone monitoring as support.

\subsection{Reducing Clinical Inertia}

Individualized targets and understanding of the patient's preferences and prognosis can provide settings where the next step of management involves de-intensification of therapies on the one hand, but an actual need to intensify therapy in those healthy older adults who may live long enough to suffer from complications due to poorly controlled diabetes, and may help create awareness regarding the heterogenous clinical presentation of diabetes in older adults, even within the same age brackets $[1,3,83]$. Although referral to an endocrinologist was found to be associated with a reduced risk of clinical inertia [66], general practitioners may intensify therapies accordingly. Continued medical education regarding emerging treatment strategies and different formulations may enhance the informed discussion with patients and reduce clinical inertia. Providers will benefit from understanding the potential advantages of newer agents, including lower risk of nocturnal hypoglycemia, fewer injections (daily, weekly), feasible titration of dosages, as well as the potential disadvantages, especially costs [84, 85], access, and barriers to injectables in general, as described above. In addition, using telehealth for remote monitoring is another potential strategy to improve management and reduce clinical inertia, but we did not find clinical trials focused on older adults with complex clinical scenarios.

Discussing diabetes care is a complex endeavor. It should also be considered that due to the natural history of the disease, as well as its chronicity and progression, older adults 
tend to require a greater number of medications (including exogenous insulin) to achieve glycemic control. We must acknowledge the potential risk of negative consequences of overtreatment, which may include polypharmacy, hypoglycemia risk, treatment burden, side effects, and costs. All these factors should be considered and balanced when selecting antihyperglycemic agents. Finally, based on our clinical practice, when we discuss the use of injectable agents, especially insulin-based products, many patients raise the concern about the long-term effects. They are worried about the common understanding that once a patient starts insulin therapy, there is no turning back. There are multiple approaches to address this situation, taking into account that diabetes is chronic and progressive.

1. Proper counseling throughout the course of the disease, even while well controlled, education and counseling on the 'worst-case scenarios' (e.g., standard practice when $\mathrm{A} 1 \mathrm{C}$ is greater than 11\%) and that diabetes progression is expected, so that we do not know what the pharmacologic needs will be in $3,5,10,20$, or more years.

2. Proper education and monitoring, even when patients are not ready to start an injectable agent, which they might well need. Always leave the opportunity open to resume the conversation, understanding and addressing what are the specific concerns they may have, and build a plan of action. This often involves giving them the opportunity to try, on their own, things they want to do, for example, "give me 3 months to improve my lifestyle"; this can be plausible if, during the visit, we detect there is actual room for improvement.

3. Let patients know that starting an injectable, such as insulin, does not imply the treatment is set in stone. Notably, patients can improve weight and lifestyle, and perhaps adherence to other medications, and while this may not occur for all, it is possible that some can make significant improvements to the point that active downtitration of injectables is required to reduce hypoglycemia risk. We have observed patients in whom the reduction of insulin dosages reaches the point where we do not observe any impact (e.g., when short-acting insulin has to be titrated below 3 units in a patient with T2D, who previously had obesity stage 2 , and then reduced their weight to the overweight category).

\section{Conclusions}

The evaluation and management of T2D in older adults is complex and challenging as the disease can impact all four geriatric domains. Working with patients and involving their caregivers is crucial to ensure proper clinical care, especially in those with functional or cognitive decline who require formal or informal assistance. There is a well-established concern regarding hypoglycemia, but hyperglycemia/uncontrolled diabetes can also lead to multiple complications in this age group. Clinicians should implement strategies to overcome barriers and clinical inertia, to ensure older patients reach their individualized glycemic targets. For some patients, injectable agents may offer advantages that can overcome barriers, including lower risk of hypoglycemia, effective glycemic control, and available weekly formulations. Unfortunately, there is a paucity of dissemination strategies to incorporate injectable agents in this age group, which makes this practice difficult.

We strongly recommend early patient education on the chronicity and progressive characteristics of this disease, as well as preparing patients for their potential future need for injectable therapies. While the newest combined agents (long-acting insulin with GLP-1 RA in one injection) have not been extensively investigated in older adults in the community or in long-term care, they could potentially be implemented at the primary care level and in long-term care, instead of basal-bolus regimens, as they may offer potential advantages, including greater adherence and less treatment burden. We recommend long-term prospective studies to monitor patient-centered (quality of life, prevention of complications, hypoglycemia, emergency room visits, and hospitalizations) and system-centered (cost-effectiveness, reduced need for skilled nursing services and formal support) outcomes, comparing different injectable agents and strategies in older adults living in the community and longterm care settings. In the meantime, the available evidence shows that implementing injectable therapies in older adults can be feasible, effective, and potentially safer than more traditional agents. Further education and engagement of general practitioners and their staff are paramount.

Costs are and should always be considered when selecting agents. However, clinical inertia should not be due to cost issues as many options are available.

Acknowledgements The contents of the paper and the opinions expressed within are those of the authors, and it was the decision of the authors to submit the manuscript for publication. The authors received writing/editorial support in the preparation of this manuscript provided by Rasilaben Vaghjiani, PhD and Nick Patterson, PhD of Excerpta Medica, funded by Sanofi US, Inc.

Author contributions WMV, HJF, and AMP were involved in the concept and design of the manuscript, analysis, and interpretation of the literature, as well as the critical review of the manuscript drafts. All authors provided final approval of the version to be submitted, and they are accountable for the accuracy and integrity of the manuscript.

\section{Compliance with Ethical Standards}

Funding Sponsor (Sanofi US Inc.) provided editorial support in the preparation and submission of this manuscript. 
Conflict of interest Willy M. Valencia and Ana M. Palacio have nothing to declare. Hermes J. Florez is a consultant (in a scientific advisory capacity) for the SENIOR study.

Open Access This article is licensed under a Creative Commons Attribution-NonCommercial 4.0 International License, which permits any non-commercial use, sharing, adaptation, distribution and reproduction in any medium or format, as long as you give appropriate credit to the original author(s) and the source, provide a link to the Creative Commons licence, and indicate if changes were made. The images or other third party material in this article are included in the article's Creative Commons licence, unless indicated otherwise in a credit line to the material. If material is not included in the article's Creative Commons licence and your intended use is not permitted by statutory regulation or exceeds the permitted use, you will need to obtain permission directly from the copyright holder. To view a copy of this licence, visit http://creativecommons.org/licenses/by-nc/4.0/.

\section{References}

1. Valencia WM, Florez H. Pharmacological treatment of diabetes in older people. Diabetes Obes Metab. 2014;16:1192-203.

2. Valencia WM, Botros D, Vera-Nunez M, Dang S. Diabetes treatment in the elderly: incorporating geriatrics, technology, and functional medicine. Curr Diab Rep. 2018;18:95.

3. Sinclair AJ, Abdelhafiz AH, Forbes A, Munshi M. Evidence-based diabetes care for older people with Type 2 diabetes: a critical review. Diabet Med. 2019;36(4):399-413.

4. Florez HJ. Glycaemic control and glycaemic variability in older people with diabetes. Lancet Diabetes Endocrinol. 2018;6(6):433-5.

5. Kirkman MS, Briscoe VJ, Clark N, et al. Diabetes in older adults: a consensus report. J Am Geriatr Soc. 2012;60:2342-56.

6. American Geriatrics Society. Expert panel on the care of older adults with diabetes mellitus. Guidelines abstracted from the American Geriatrics Society Guidelines for improving the care of older adults with diabetes mellitus: 2013 update. J Am Geriatr Soc. 2013;2013(61):2020-6.

7. International Diabetes Federation. Global guideline for managing older people with type 2 diabetes. 2013. https://www.idf.org/elibrary/guidelines/78-global-guideline-for-managing-older-peopl e-with-type-2-diabetes.html. Accessed May 2019.

8. Inzucchi SE, Bergenstal RM, Buse JB, et al. Management of hyperglycaemia in type 2 diabetes, 2015: a patient-centred approach. Update to a position statement of the American Diabetes Association and the European Association for the Study of Diabetes. Diabetologia. 2015;58:429-42.

9. Davies MJ, D'Alessio JF, Fradkin J, et al. Management of hyperglycemia in type 2 diabetes, 2018. A consensus report by the American Diabetes Association (ADA) and the European Association for the Study of Diabetes (EASD). Diabetes Care. 2018;2018(41):2669-701.

10. American Diabetes Association. Standards of medical care in diabetes-2019. Diabetes Care. 2019;42(Suppl 1):S1-152.

11. Peyrot M, Barnett AH, Meneghini LF, Schumm-Draeger PM. Insulin adherence behaviors and barriers in the multinational Global Attitudes of Patients and Physicians in Insulin Therapy study. Diabet Med. 2012;29:682-9.

12. Polonsky WH, Herny RR. Poor medication adherence in type 2 diabetes: recognizing the scope of the problem and its key contributors. Patient Prefer Adherence. 2016;10:1299-307.

13. Fu SN, Wong CK, Chin WY, Luk W. Association of more negative attitude towards commencing insulin with lower glycosylated hemoglobin (HbA1c) level: a survey on insulin-naïve type 2 diabetes mellitus Chinese patients. J Diabetes Metab Disord. 2016;15:3.

14. de Jesús G-GJ, Gastaldelli A, DeFronzo RA, Lertwattanarak $\mathrm{R}$, Holst JJ, Musi N. Older subjects with $\beta$-cell dysfunction have an accentuated incretin release. J Clin Endocrinol Metab. 2018;103:2613-9.

15. Sinclair A, Dunning T, Rodriguez-Mañas L. Diabetes in older people: new insights and remaining challenges. Lancet Diabetes Endocrinol. 2015;3:275-85.

16. Sinclair AJ, Abdelhafiz A, Dunning T, et al. An international position statement on the management of frailty in diabetes mellitus: summary of recommendations 2017. J Frailty Aging. 2018;7:10-20.

17. Valencia WM, Danet M, Florez H, Bourdel-Marchasson I. Assessment procedures including comprehensive geriatric assessment. In: Sinclair A, Dunning T, Rodríguez Mañas L, Munshi M, editors. Diabetes in old age. 4th ed. Hoboken: Wiley-Blackwell; 2017. p. 43-53.

18. Munshi MN, Segal AR, Suhl E, et al. Frequent hypoglycemia among elderly patients with poor glycemic control. Arch Intern Med. 2011;171:362-4.

19. Sinclair AJ, Bellary S. Preventing hypoglycaemia: an elusive quest. Lancet Diabetes Endocrinol. 2016;4:635-6.

20. Fu H, Xie W, Curtis B, Schuster D. Identifying factors associated with hypoglycemia-related hospitalizations among older adults with T2DM in the US: a novel approach using influential variable analysis. Curr Med Res Opin. 2014;30:1787-93.

21. Arredondo A, Aviles R. Healthcare costs in older adults with diabetes mellitus: challenges for health systems and for society. J Am Geriatr Soc. 2015;63:2421-3.

22. American Diabetes Association. Economic costs of diabetes in the US in 2017. Diabetes Care. 2018;41:917-28.

23. Valencia WM, Stoutenberg M, Florez H. Weight loss and physical activity for disease prevention in obese older adults: an important role for lifestyle management. Curr Diab Rep. 2014;14:539.

24. Munshi MN, Florez H, Huang ES, et al. Management of diabetes in long-term care and skilled nursing facilities: a position statement of the American Diabetes Association. Diabetes Care. 2016;39:308-18.

25. Perkovic V, Jardine MJ, Neal B, et al. Canagliflozin and renal outcomes in type 2 diabetes and nephropathy. N Engl J Med. 2019 (Epub ahead of print).

26. Sharma R, Razdan K, Kuhad A, Kuhad A. Ertugliflozin for the treatment of type 2 diabetes. Drugs Today. 2019;55:167-75.

27. Aroda VR. A review of GLP-1 receptor agonists: evolution and advancement, through the lens of randomised controlled trials. Diabetes Obes Metab. 2018;20(Suppl 1):22-33.

28. Marso SP, Daniels GH, Brown-Frandsen K, et al. Liraglutide and cardiovascular outcomes in type 2 diabetes. N Engl J Med. 2016;375:311-22.

29. Marso SP, Bain SC, Consoli A, et al. Semaglutide and cardiovascular outcomes in patients with type 2 diabetes. $\mathrm{N}$ Engl J Med. 2016;375:1834-44.

30. Gerstein HC, Colhoun HM, Dagenais GR, et al. Dulaglutide and cardiovascular outcomes in type 2 diabetes (REWIND): a doubleblind, randomized placebo-controlled trial. Lancet. 2019. https:// doi.org/10.1016/S0140-6736(19)31149-3.

31. Pfeffer MA, Claggett B, Diaz R, et al. Lixisenatide in patients with type 2 diabetes and acute coronary syndrome. N Engl J Med. 2015;373:2247-57.

32. Holman RR, Bethel MA, Mentz RJ, et al. Effects of once-weekly exenatide on cardiovascular outcomes in type 2 diabetes. N Engl J Med. 2017;377:1228-39. 
33. Bahtiyar G, Pujals-Kury J, Sacerdote A. Cardiovascular effects of different GLP-1 receptor agonists in patients with type 2 diabetes. Curr Diab Rep. 2018;18:92.

34. Meneilly GS, Roy-Duval C, Alawi H, et al. Lixisenatide therapy in older patients with type 2 diabetes inadequately controlled on their current antidiabetic treatment: the GetGoal-O randomized trial. Diabetes Care. 2017;40:485-93.

35. Thong KY, Gupta PS, Blann AD, Ryder RE. The influence of age and metformin treatment status on reported gastrointestinal side effects with liraglutide treatment in type 2 diabetes. Diabetes Res Clin Pract. 2015;109:124-9.

36. Bode BW, Brett J, Falahati A, Pratley RE. Comparison of the efficacy and tolerability profile of liraglutide, a once-daily human GLP-1 analog, in patients with type 2 diabetes $\geq 65$ and $<65$ years of age: a pooled analysis from phase III studies. Am J Geriatr Pharmacother. 2011;9:423-33.

37. Raccah D, Miossec P, Esposito V, Niemoeller E, Cho M, Gerich J. Efficacy and safety of lixisenatide in elderly ( $\geq 65$ years old) and very elderly ( $\geq 75$ years old) patients with type 2 diabetes: an analysis from the GetGoal phase III programme. Diabetes Metab Res Rev. 2015;31:204-11.

38. Ericsson A, Fridhammar A. Cost-effectiveness of once-weekly semaglutide versus dulaglutide and lixisenatide in patients with type 2 diabetes with inadequate glycemic control in Sweden. J Med Econ. 2019;23:1-9.

39. Riddle MC, Rosenstock J, Gerich J. The Treat-to-Target trial: randomized addition of glargine or human NPH insulin to oral therapy of type 2 diabetic patients. Diabetes Care. 2003;26:3080-6.

40. Lee P, Chang A, Blaum C, Vlajnic A, Gao L, Halter J. Comparison of safety and efficacy of insulin glargine and neutral protamine Hagedorn insulin in older adults with type 2 diabetes mellitus: results from a pooled analysis. J Am Geriatr Soc. 2012;60:51-9.

41. Pandya N, DiGenio A, Gao L, Patel M. Efficacy and safety of insulin glargine compared to other interventions in younger and older adults: a pooled analysis of nine open-label, randomized controlled trials in patients with type 2 diabetes. Drugs Aging. 2013;30:429-38.

42. Buse JB, Wolffenbuttel BH, Herman WH, et al. DURAbility of basal versus lispro mix 75/25 insulin efficacy (DURABLE) trial 24-week results: safety and efficacy of insulin lispro mix 75/25 versus insulin glargine added to oral antihyperglycemic drugs in patients with type 2 diabetes. Diabetes Care. 2009;32:1007-13.

43. Buse JB, Wolffenbuttel BH, Herman WH, et al. The DURAbility of Basal versus Lispro mix 75/25 insulin Efficacy (DURABLE) trial: comparing the durability of lispro mix $75 / 25$ and glargine. Diabetes Care. 2011;34:249-55.

44. Wolffenbuttel BH, Klaff LJ, Bhushan R, Fahrbach JL, Jiang H, Martin S. Initiating insulin therapy in elderly patients with type 2 diabetes: efficacy and safety of lispro mix 25 vs. basal insulin combined with oral glucose-lowering agents. Diabet Med. 2009;26:1147-55.

45. Jovanovič L, Peters AL, Jiang HH, Hardin DS. Durability of glycemic control with insulin lispro mix 75/25 versus insulin glargine for older patients with type 2 diabetes. Aging Clin Exp Res. 2014;26:115-21.

46. Aroda VR, Rosenstock J, Wysham C, et al. Efficacy and safety of LixiLan, a titratable fixed-ratio combination of insulin glargine plus lixisenatide in type 2 diabetes inadequately controlled on basal insulin and metformin: the LixiLan-L randomized trial. Diabetes Care. 2016;39:1972-80.

47. Lingvay I, Handelsman Y, Linjawi S, et al. Efficacy and safety of IDegLira in older patients with type 2 diabetes. Endocr Pract. 2019;25:144-55.

48. Bolli GB, Riddle MC, Bergenstal RM, et al. New insulin glargine $300 \mathrm{U} / \mathrm{ml}$ compared with glargine $100 \mathrm{U} / \mathrm{ml}$ in insulin-naïve people with type 2 diabetes on oral glucose-lowering drugs: a randomized controlled trial (EDITION 3). Diabetes Obes Metab. 2015;17:386-94.

49. Yki-Järvinen H, Bergenstal R, Ziemen M, et al. New insulin glargine 300 units $/ \mathrm{mL}$ versus glargine 100 units $/ \mathrm{mL}$ in people with type 2 diabetes using oral agents and basal insulin: glucose control and hypoglycemia in a 6-month randomized controlled trial (EDITION 2). Diabetes Care. 2014;37:3235-43.

50. Russell-Jones D, Gall MA, Niemeyer M, Diamant M, Del Prato $\mathrm{S}$. Insulin degludec results in lower rates of nocturnal hypoglycaemia and fasting plasma glucose vs. insulin glargine: a metaanalysis of seven clinical trials. Nutr Metab Cardiovasc Dis. 2015;25:898-905.

51. Yale JF, Pettus JH, Brito-Sanfiel M, et al. The effect of concomitant DPPIVi use on glycaemic control and hypoglycaemia with insulin glargine $300 \mathrm{U} / \mathrm{mL}$ (Gla-300) versus insulin glargine 100 $\mathrm{U} / \mathrm{mL}$ (Gla-100) in people with type 2 diabetes: a patient-level meta-analysis of EDITION 2 and 3. PLoS One. 2018;13:0190579.

52. Ritzel R, Roussel R, Giaccari A, Vora J, Brulle-Wohlhueter C, Yki-Järvinen H. Better glycaemic control and less hypoglycaemia with insulin glargine $300 \mathrm{U} / \mathrm{mL}$ vs glargine $100 \mathrm{U} /$ $\mathrm{mL}$ : 1-year patient-level meta-analysis of the EDITION clinical studies in people with type 2 diabetes. Diabetes Obes Metab. 2018;20:541-8.

53. Bailey TS, Zhou FL, Gupta RA, et al. Glycaemic goal attainment and hypoglycaemia outcomes in type 2 diabetes patients initiating insulin glargine 300 units $/ \mathrm{mL}$ or 100 units $/ \mathrm{mL}$ : real-world results from the DELIVER Naïve cohort study. Diabetes Obes Metab. 2019;21:1596-605.

54. Bailey TS, Wu J, Zhou FL, et al. Switching to insulin glargine 300 units $/ \mathrm{mL}$ in real-world older type 2 diabetes patients (DELIVER 3). Diabetes Obes Metab. 2019. https://doi.org/10.1111/ dom.13818.

55. Ritzel R, Harris SB, Baron $\mathrm{H}$, et al. A randomized controlled trial comparing efficacy and safety of insulin glargine $300 \mathrm{Units} / \mathrm{mL}$ versus 100 units $/ \mathrm{mL}$ in older people with type 2 diabetes: results from the SENIOR Study. Diabetes Care. 2018;41:1672-80.

56. Marso SP, McGuire DK, Zinman B, et al. Efficacy and safety of degludec versus glargine in type 2 diabetes. N Engl J Med. 2017;377:723-32.

57. Cohen CM, Thorsted BL, Wolden ML, Chodick G, Karasik A. Improved glycemic control achieved by switching to insulin degludec in insulin-treated patients with type 2 diabetes in a realworld setting: a non-interventional, retrospective cohort study. Diab Ther. 2017;8:1047-55.

58. Nagai Y, Murakami M, Igarashi K, et al. Efficacy and safety of thrice-weekly insulin degludec in elderly patients with type 2 diabetes assessed by continuous glucose monitoring. Endocr $\mathrm{J}$. 2016;63:1099-106.

59. Ng CJ, Lai PS, Lee YK, Azmi SA, Teo CH. Barriers and facilitators to starting insulin in patients with type 2 diabetes: a systematic review. Int J Clin Pract. 2015;69:1050-70.

60. Lipska KJ, Ross JS, Wang Y, et al. National trends in US hospital admissions for hyperglycemia and hypoglycemia among Medicare beneficiaries, 1999 to 2011. JAMA Intern Med. 2014;174:1116-24.

61. Pistrosch F, Ganz X, Bornstein SR, Birkenfeld AL, Henkel E, Hanefeld M. Risk of and risk factors for hypoglycemia and associated arrhythmias in patients with type 2 diabetes and cardiovascular disease: a cohort study under real-world conditions. Acta Diabetol. 2015;52:889-95.

62. Johnston SS, Conner C, Aagren M, Ruiz K, Bouchard J. Association between hypoglycaemic events and fall-related fractures in Medicare-covered patients with type 2 diabetes. Diabetes Obes Metab. 2012;14:634-43.

63. Peyrot M, Rubin RR, Lauritzen $\mathrm{T}$, et al. Resistance to insulin therapy among patients and providers: results of the cross-national 
Diabetes Attitudes, Wishes, and Needs (DAWN) study. Diabetes Care. 2005;28:2673-9.

64. Lin J, Zhou S, Wei W, Pan C, Lingohr-Smith M, Levin P. Does clinical inertia vary by personalized A1c goal? A study of predictors and prevalence of clinical inertia in a US managed-care setting. Endocr Pract. 2016;22:151-61.

65. Paul SK, Klein K, Thorsted BL, Wolden ML, Khunti K. Delay in treatment intensification increases the risks of cardiovascular events in patients with type 2 diabetes. Cardiovasc Diabetol. 2015; $14: 100$.

66. Osataphan S, Chalermchai T, Ngaosuwan K. Clinical inertia causing new or progression of diabetic retinopathy in type 2 diabetes: a retrospective cohort study. J Diabetes. 2017;9:267-74.

67. Giorda CB, Cercone S, Nada E, ACCADEMY Study Group. Results of the Adequacy of glycemiC Control in pAtients with type 2 Diabetes mEllitus treated with Metformin monotherapY at the maximal-tolerated dose (ACCADEMY) study. Endocrine. 2016;52:507-15

68. Levin PA, Wei W, Zhou S, Xie L, Baser O. Outcomes and treatment patterns of adding a third agent to 2 OADs in patients with type 2 diabetes. J Manag Care Spec Pharm. 2014;20:501-12.

69. Yu M, Mody R, Lando LF, et al. Characteristics associated with the choice of first injectable agent therapy among US patients with type 2 diabetes. Clin Ther. 2017;39:2399-408.

70. Heintjes EM, Overbeek JA, Hall GC, et al. Factors associated with type 2 diabetes mellitus treatment choice across four European countries. Clin Ther. 2017;39:2296-310.

71. Zinman B, DeVries JH, Bode B, et al. Efficacy and safety of insulin degludec three times a week versus insulin glargine once a day in insulin-naïve patients with type 2 diabetes: results of two phase 3, 26 week, randomised, open-label, treat-to-target, non-inferiority trials. Lancet Diabetes Endocrinol. 2013;1:123-31.

72. Xue X, Ren Z, Zhang A, Yang Q, Zhang W, Liu F. Efficacy and safety of once-weekly glucagon-like peptide-1 receptor agonists compared with exenatide and liraglutide in type 2 diabetes: a systemic review of randomised controlled trials. Int J Clin Pract. 2016;70:649-56.

73. Rosenstock J, Fonseca VA, Gross JL, et al. Advancing basal insulin replacement in type 2 diabetes inadequately controlled with insulin glargine plus oral agents: a comparison of adding albiglutide, a weekly GLP-1 receptor agonist, versus thrice-daily prandial insulin lispro. Diabetes Care. 2014;37:2317-25.

74. Rosenstock J, Aronson R, Grunberger G, et al. Benefits of LixiLan, a titratable fixed-ratio combination of insulin glargine plus lixisenatide, versus insulin glargine and lixisenatide monocomponents in type 2 diabetes inadequately controlled on oral agents: the LixiLan-O randomized trial. Diabetes Care. 2016;39:2026-35.
75. Buse JB, Vilsbøll T, Thurman J, et al. Contribution of liraglutide in the fixed-ratio combination of insulin degludec and liraglutide (IDegLira). Diabetes Care. 2014;37:2926-33.

76. Palacio A, Garay D, Langer B, Taylor J, Wood BA, Tamariz L. Motivational interviewing improves medication adherence: a systematic review and meta-analysis. J Gen Intern Med. 2016;31:929-40.

77. Korytkowski M, Niskanen L, Asakura T. FlexPen: addressing issues of confidence and convenience in insulin delivery. Clin Ther. 2005;27 Suppl B:S89-100.

78. Slabaugh SL, Bouchard JR, Li Y, Baltz JC, Meah YA, Moretz DC. Characteristics relating to adherence and persistence to basal insulin regimens among elderly insulin-naïve patients with type 2 diabetes: pre-filled pens versus vials/syringes. Adv Ther. 2015;32:1206-21.

79. Xie L, Zhou S, Pinsky BW, Buysman EK, Baser O. Impact of initiating insulin glargine disposable pen versus vial/syringe on realworld glycemic outcomes and persistence among patients with type 2 diabetes mellitus in a large managed care plan: a claims database analysis. Diabetes Technol Ther. 2014;16:567-75.

80. Diamant M, Van Gaal L, Stranks S, et al. Once weekly exenatide compared with insulin glargine titrated to target in patients with type 2 diabetes (DURATION-3): an open-label randomised trial. Lancet. 2010;375:2234-43.

81. Diamant M, Van Gaal L, Guerci B, et al. Exenatide once weekly versus insulin glargine for type 2 diabetes (DURATION-3): 3-year results of an open-label randomised trial. Lancet Diabetes Endocrinol. 2014;2:464-73.

82. Aronson RI, Gibney MA, Oza K, Bérubé J, Kassler-Taub K, Hirsch L. Insulin pen needles: effects of extra-thin wall needle technology on preference, confidence, and other patient ratings. Clin Ther. 2013;35:923-33.

83. Schernthaner G, Schernthaner-Reiter MH. Diabetes in the older patient: heterogeneity requires individualization of therapeutic strategies. Diabetologia. 2018;61:1503-16.

84. George CM, Byun A, Howard-Thompson A. New injectable agents for the treatment of type 2 diabetes Part 1 -injectable insulins. Am J Med. 2018;131(7):752-4.

85. George C, Byun A, Howard-Thompson A. New injectable agents for the treatment of Type 2 diabetes part 2-glucagon-like peptide-1 (GLP-1) agonists. Am J Med. 2018;131(11):1304-6. 